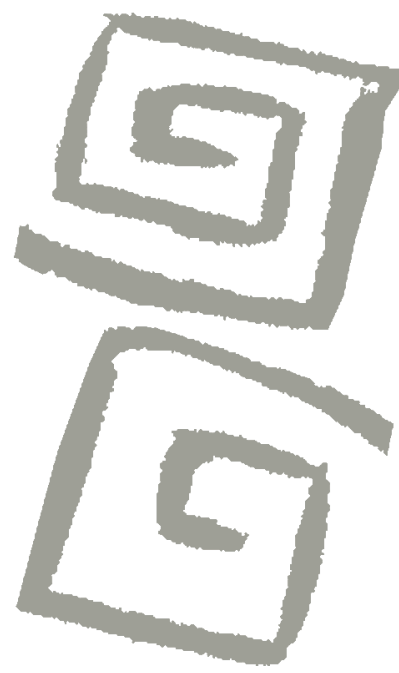

\title{
Tradición, improvisación y modernidad en el chamanismo maya yucateco: El arte suhuy de Juan Cob, $h$-men de Yaxcabá
}

\author{
Tradition, improvisation and modernity in Yucatecan \\ Mayan shamanism: The suhuy art of Juan Cob, \\ h-men of Yaxcabá
}

Michel Boccara ${ }^{1}$

'Etnólogo, cineasta. Investigador, Centre National de la Recherche Scientifique, Toulouse, Francia. $\bowtie$
RESUMEN A través de la historia de un chamán maya yucateco ( $h$-men), este artículo analiza los cambios y las continuidades en el chamanismo yucateco y, más específicamente, en una de sus funciones principales: tsak, "curar". Los resultados presentados aquí son parte de un trabajo de campo de 40 años, de 1976 a 2016. El autor vive en una comunidad del centro de Yucatán (Tabi, Sotuta) y ha realizado varias investigaciones sobre el chamanismo yucateco en comunidades de los estados de Yucatán, Campeche y Quintana Roo. Juan Cob, h-men de Yaxcabá, no es solo un informante sino también vecino, amigo del autor con el cual realizó varias películas.

PALABRAS CLAVES Medicina Tradicional; Chamanismo.

ABSTRACT Through the history of a Yucatecan Mayan shaman ( $h$-men), this article analyzes the changes and continuities in Yucatecan shamanism and, more specifically, in one of its main functions: tsak, healing. The results presented here are part of fieldwork carried out over 40 years, from 1976 to 2016. The author lives in a community in central Yucatán (Tabi, Sotuta) and has carried out a number of research studies on Yucatecan shamanism in communities in the Mexican states of Yucatán, Campeche and Quintana Roo. Juan Cob, h-men of Yaxcabá, is not only an informant but also the author's friend and neighbor, with whom he has created a number of films.

KEY WORDS Traditional Medicine; Shamanism. 


\section{IMPROVISAR O EL USO ORIGINAL DE LA PALABRA}

"Il faut être absolument moderne" (Hay que ser absolutamente moderno). Arthur Rimbaud, Une saison en enfer (Una temporada en el infierno)

La traducción de suhuy por "virgen" es privilegiada en los diccionarios, con una variación, aparentemente extraña, suhuytal, "volverse virgen", es decir, regresar al estado original. El ritual de los Bacabes ${ }^{(1,2)}$, el más importante manuscrito en lengua maya de la época colonial, atestigua la importancia de esta noción: aparece 34 veces para calificar la madre cósmica o la aguja original (suhuy puts') que permitió la perforación del útero cósmico para dar a luz al mundo.

En el lenguaje corriente, se habla de agua suhuy en los cenotes o grutas que nunca vieron la luz del sol, de una ropa suhuy o "nueva", que nunca fue cargada o llevada por un humano, de un trabajo suhuy, hecho en estado de "pureza", de momentos suhuy, como suhuy ak'ab, "media noche, origen de la noche", o suhuy k'in, "medio día, origen del día". En la lengua maya "mediodía" es también el origen del tiempo/día y "media noche", el origen de la noche/creación cósmica: los días, como las noches, empiezan a las doce.

En 2011, descubrí un último significado de la palabra suhuy con Giovani Balam, nieto de Luis Balam, h-men de San Francisco. Unas semanas después, Juan daba confirmación a esta traducción: un suhuy meyah, un trabajo suhuy es también un trabajo improvisado(3).

\section{PASARON 40 AÑOS...}

Cuando llegué a la región, hace 40 años, había h-menes en todos los pueblos. Mi vecino, don Tono, empezó a trabajar como h-men en 1983, el año que presenté mi doctorado. Primero acompañó a los h-menes más antiguos, y cuando ellos se volvieron muy viejos, hasta morir, se volvió h-men y trabajó en Tabi, Tibolon y Sotuta, los principales pueblos del municipio de Sotuta.

En Yaxcabá, cabecera del municipio más grande de Yucatán, colindando con el de Sotuta, había varios $h$-menes pertenecientes a varias escuelas, y entre ellos Juan, un joven $h$-men doce años mayor que yo.

Es importante aclarar que $h$-men no es el único término que se puede traducir por "chamán". Tenemos también los términos de ah k'in, chilam, espiritista y way, este último muy polisémico. Todos esos términos se siguen empleando de manera muy marginal por algunos. Para un estudio detallado de esas "categorías" de chamanes, ver mi libro Saints, chamanes et pasteurs: La religion populaire des Mayas, $I^{(4)}$.

Una de mis primeras películas, rodada en 1989, Ilamada Una conversación con Don Juan, es un rodaje en un solo plano, en el que se muestra una plática de 13 minutos entre Juan y $\mathrm{yo}^{(5)}$. De acuerdo con una técnica improvisada ese día, y que acompañó después nuestros demás encuentros, cuando la conversación empieza a desarrollarse, saco la cámara. Ese día, Juan fue el primero en filmar y después de unos minutos me dio el instrumento de trabajo, u nukul u meyah, para seguir la investigación.

Mi primera pregunta fue acerca del espiritismo, uno de los puntos clave del chamanismo yucateco ${ }^{(5)}$ :

Michel: $-i B a x$ forma ku meyah un tu espiritista? [¿Cómo trabaja un espiritista?].

Juan: $-i$ Bax ten u meyah wa bax klasi ku meyahtik? [¿Cómo yo trabajo o qué clase de trabajo hacen?].

Michel: -Bax forma, bax klasi ku meyahtik. [Qué clase de trabajo hacen]. Juan: -Le espiritista ku korporar ti ula espiritus, ka meyanak, ti tsak, ti u bet operación, le operación invisible kya'ala, ku xotik mak, ma chikan tux ku xotke. [Los espiritistas incorporan otro espíritu para trabajar con él, para curar, para hacer una operación invisible como la llaman, donde no se ve qué se le cortó a una persona]. Michel: -iEntonces ku inkorporar ulak 
pixan? [iY entonces incorporan otro espíritu?]. Juan:-lchi le bako. [En su carne]. Michel: -Ichi le kuerpo. [En su cuerpo]. Juan: -Ka meyah nak yete.

[Para trabajar con él].

Michel: $-i T a l$ vez yan uchbe makobo, uchbe yerbateros ku inkorporar? [iTal vez son las personas antiguas, los yerbateros antiguos que incorporan?] Juan:-Leti uchbe yerbateros ku meyaho beyo espiritual mayormente. Letiobe yohlo bax tsak u betko, yohlo bax... ti yohlo bix u tsako mak ti este... un pe koha'ani ku padesertik, kohanilo incurableo men a doktor... [Son los antiguos yerbateros que trabajan en forma espiritual. Saben cuáles medicamentos preparar, saben cómo curar la gente, las enfermedades que padecen, las enfermedades incurables por el doctor...]

En aquel tiempo, acababa de integrar, en Francia, lo que iba a ser mi equipo de investigación "Psicoanálisis y práctica social", y estudiaba la mitología a través de los textos de Freud, Lacan, Klein... Cuando Juan me dijo que los espiritistas hacían operaciones espirituales, sin cortar, le contesté que también existían doctores en Europa que operaban sin cortar y que se llamaban psicoanalistas: "Hay doctores especialistas que trabajan espiritualmente, que hacen también operaciones espirituales... se llaman psicoanalistas".

Unos años más tarde, cuando me instalé en el sur de Francia, donde me encontré también con chamanes pero que trabajan de otra manera. Por ejemplo, mi amigo Pierre Capelle trabajaba con el espíritu de los árboles que pone en contacto con sus pacientes. Como lo escribí en el libro que redactamos en común ${ }^{(6)}$, el árbol es como el péndulo (otra herramienta de adivinación), pero mejor que el péndulo es un sujeto: según Pierre, el árbol contesta a nuestras preguntas si sabemos formularlas y si decide contestarnos, ya que los árboles tienen una voluntad y un carácter: no son todos buenos, ni con buena disposición ${ }^{(6)}$.

Pero a diferencia de Yucatán, los h-menes franceses son clandestinos ya que pueden ser perseguidos por el poderoso "Colegio de médicos" bajo el cargo de "ejercicio ilegal de la medicina". Pero esa clandestinidad los protege porque, y no es la mínima de las paradojas, existen tantos curanderos en mi pequeño rincón del campo francés como en los municipios de Sotuta y Yaxcabá reunidos, los cuales abarcan una superficie más grande.

En Yucatán, asistí, durante estos 40 últimos años, a una transformación radical de las formas de producción, de los modos de vivir, de las costumbres y creencias... Casi todo cambió... y, sin embargo, nada cambió. Así contaba el viejo gatopardo, Giuseppe Tomasi di Lampedusa "todo debe cambiar para que nada cambie..." ${ }^{\prime(7)}$.

Nada cambió:

Aún se habla maya.

Aún se cultiva milpa.

Aún se come omsikil en los viernes santos.

Las mujeres aún llevan ipiles.

Las casas aún tienen techo de palma.

Y Juan aún hace el $k^{\prime}$ ex y las santiguadas...

Y todo cambió:

Los niños aprenden el castellano antes de la maya y existe hoy adolescentes que casi no lo entienden.

Los jóvenes prefieren el trabajo asalariado en la ciudad a la milpa y casi nadie va a trabajar en las milpas de otros.

El onsikil ya se come con tortillas hechas en máquina y hasta con francés (pan de trigo).

Los techos de palma son más escasos y las casas de bloques toman poco a poco el lugar de las casas de madera.

Y, en la clínica de Juan, su nieta hace masajes faciales con crema para bajar de peso... mientras Juan se perfila a ser el último h-men de Yaxcabá; aunque existe todavía otro $h$-men, pero es un espiritista y aprendió su trabajo en Cancún, donde florecen los espiritistas.

Es preciso aclarar que no todos los espiritistas son $h$-menes lo que permite distinguir esas dos formas de chamanes ${ }^{(4)}$. Y al mismo tiempo que los $h$-menes desaparecen, nace una nueva categoría de médicos: los "médicos tradicionales". 


\section{H-men y médico tradicional}

$H$-men o Ah men es una de las denominaciones del "chamán" en Yucatán. En los diccionarios del maya colonial, el término no designa específicamente al chamán sino más bien al maestro, el que domina un oficio "maestro o artífice de cualquier dote u oficio, y oficial"(8) y tenemos enseguida una larga lista de ah men que remiten a distintos oficios, entre los cuales encontramos ah men loo', "los brujos". Solo en las fuentes más recientes, fechadas en el siglo XX, encontramos h-men/ah men con el sentido de yerbatero, considerando al yerbatero como "diestro en casi cualquier arte y profesión"(8). Ya que los diccionarios son sexistas, no encontramos la forma $x$-men, femenino de $h$-men, que todavía existe en el idioma corriente y designa el especialista femenino.

Podemos plantear entonces como hipótesis que el término de $h$-men apareció recientemente para designar al yerbatero, es decir al chamán. Hace 40 años, todavía existía un término -algunos ancianos aún deben conocerlo y tal vez en el oriente es todavía usado- que era empleado como sinónimo de h-men: ah k'in. Este término, a diferencia de $h$-men, se encuentra en casi todas las fuentes antiguas y, en particular, en los documentos de la inquisición española ${ }^{(9)}$. También fue el nombre maya asignado al sacerdote español.

$\mathrm{Si}$ la hipótesis de la aparición reciente (fin del siglo XIX, principio del siglo XX) del término $h$-men para designar al chamán es exacta, entonces podemos pensar que la aparición de ese término coincidió con una transformación de la función: el h-men se volvió más polivalente y se apropió de algunas funciones del sacerdote y del médico extranjero o $d z u l$, del mismo modo en que estos últimos se apropiaron de las de aquél.

Sabemos que existían médicos dzules que utilizaban plantas tradicionales, así como, muy probablemente, curanderos españoles que utilizaban prácticas míticas mayas y africanas. Los negros africanos que, al principio de la época colonial, representaban un grupo numéricamente importante, desaparecieron, incorporándose poco a poco a los grupos "mestizos" y mayas yucatecos. Sin embargo, varios rituales yucatecos quedaron influenciados por la cultura "negra" $y$, particularmente, el $k^{\prime}$ ex. Los negros permanecen como grupo importante en el estado de Belize, una de las entidades políticas de la península yucateca. Las investigaciones recientes de Mathews Restall ${ }^{(10)}$ permiten documentar mejor el lugar intermedio de los africanos entre los españoles y los autóctonos.

El libro del judío ${ }^{(11,12)}$, atribuido a un médico dzul de Valladolid, Giovanni Francesco Mayoli, que firmaba con el seudónimo Ricardo Ossado, es un ejemplo de ello. Del otro lado los ah ki'nob mayas se apropiaban de los nuevos medicamentos y las nuevas "tecnologías espirituales", como el espiritismo importado de Francia, que consistía en incorporar, como lo explica don Juan, un espíritu que habla por nuestra boca. Y Juan cita el caso de una espiritista que no habla español pero que incorpora un espíritu que habla ese idioma. Así, los maestros dzules toman su lugar al lado de los maestros mayas: Allan Kardec, que vivió en Lyon (Francia) en el siglo XIX, es invocado en los cantos de Juan con Máximo Cen, Antiguo h-men de Cuch Holoch, una pequeña población ubicada en la frontera de Yucatán y Campeche, entre Halachó y Nunkini.

Hippolyte Rivail, que utilizó el pseudónimo de Allan Kardec, nació en Lyon en 1804. En una sesión de magnetismo, un médium revela a Hippolyte Rivail que en una vida anterior fue druida con el nombre de Allan Kardec, y desde ese momento Rivail utiliza el nombre de Kardec. En 1857, Kardec publica El libro de los espíritus (Le livre des Esprits) basándose sobre cuadernos de transcripciones de palabras de médiums. Este libro se vuelve el libro fundamental del espiritismo mundial ${ }^{(13)}$.

Asistimos hoy, a principios del siglo XXI, a una mutación del mismo tipo: el $h$-men clásico tiende a desaparecer poco a poco y cede su lugar a otro tipo de especialista que toma el nombre de "médico tradicional" mientras aparecen nuevos tipos de chamanes "new age" y un turismo chamánico, que se da también en otras partes del mundo. Si embargo, el espiritista, aparecido probablemente a 
fines del siglo XIX y que se fusionó en parte con el $h$-men -Juan Ilama $h$-men al espiritista que ejerce en Yaxcabá- no solo ha persistido, sino que se ha desarrollado principalmente en las ciudades.

El nombre de "médico tradicional" ya no es maya y sigue el camino inaugurado por los espiritistas que importaron su nombre de Europa. Y, al mismo tiempo que cambia el nombre, asistimos a un cambio de función:

- El médico tradicional -tenemos varios en Tabi pero ya no hay ningún h-men- cura con plantas pero ya no utiliza cantos, rezos, y rituales.

- El médico tradicional es, en parte, una creación de las instituciones mexicanas y lleva todo el peso de la ambigüedad implícita en la noción "tradición".

- Pero el médico tradicional es también una creación autóctona, un medio encontrado por los campesinos mayas para resistir y adaptarse a la modernización y a la globalización.

Hay que aclarar que el predecesor del médico tradicional, el h-men, ya utilizaba, y utiliza todavía, rezos en español de sus concurrentes los sacerdotes y que el cha'chak, la principal ceremonia agrícola contemporánea del estado de Yucatán, es también una misa milpera y muy bien puede ser contemporánea de la "invención" del h-men en el siglo XIX porque las más antiguas menciones de esta ceremonia fechan de la mitad de ese siglo.

Juan José Hernández, hombre político originario de Valladolid, menciona en un artículo de $1845^{(14)}$ : "el kuch, el tich, el cha'chak y el pochob". El pochob o pocho'o, según Lázaro Suarez de Nunkini, es el nombre maya para el carnaval. Para más datos y bibliografía sobre el cha'chak y los rituales mayas remito al tomo 8 "Chak y sus caballos: mitología de la lluvia y de la fertilidad"(15) y al tomo 15 "Herramientas de investigación: Vocabulario, bibliografía, glosario"(3) de LoS laberintos sonoros: Enciclopedia de la mitología maya yucateca, y al libro Saints, chamanes et pasteurs: La religion populaire des Mayas $(I I)^{(4)}$.

\section{El arte suhuy de Juan Cob, h-men de Yaxcabá}

Sin embargo, el h-men todavía no ha desaparecido, ya que aún, si bien está en decrecimiento, cohabita con el médico tradicional. $\mathrm{Y}$ hay que aclarar que también depende de las regiones:

- En Nunkini, cerca de Cuch Holoch, hay todavía cinco h-menes, de los cuales uno de ellos tiene 40 años y es bibliotecario de la escuela secundaria del pueblo.

- En el oriente de Yucatán, el h-men resiste mejor que en la zona centro.

Pero, aun en esta zona centro donde el h-men está en peligro, existe en Yaxcabá un $h$-men que resiste y, mientras sus colegas desaparecen unos tras otros, afirma con humor $y$ alegría, así como con sabiduría y locura, la persistencia de su oficio de ah men. Es mi amigo Juan Cob Balam de Yaxcabá, que hoy tiene 73 años pero que aparenta diez menos, y que bien podría vivir y trabajar 30 años más tal como los más famosos de sus antepasados.

¿Por qué Juan resistió? Su secreto reside en su formidable capacidad de adaptación y en su talento, yo diría su genio, para incorporar todas las formas nuevas en su práctica, para decirlo en una sola palabra, en su modernismo. A continuación, expongo algunos aspectos de su práctica.

\section{Tradición e improvisación}

Leidy, la nieta de Juan, que hoy es su asistente, decidió diseñar un sitio en Internet sobre el trabajo de su abuelo, más bien una página de Facebook con el nombre de Jardín botánico Medicina Herbolaria Yaxcabá. En esta página, Leidy propone varios nuevos servicios: tratamiento facial, aromaterapia y medicina estética general, entre otros. Hoy Internet y los nuevos medios se han vuelto ineludibles para tener una clientela ya que sin clientela un h-men no puede sobrevivir. No solo hay que respetar la tradición sino también adaptarse a las "leyes del mercado". 
Juan tiene, en Yaxcabá, un distinguido antepasado en términos de adaptación: el famoso doctor Nacho, fallecido hace poco, que había ganado la confianza de todos los campesinos. Y ¿quién era el padre del doctor Nacho? Un h-men que, para transmitir su conocimiento, hizo de su hijo un médico. De allí que medicina tradicional y medicina alopática tienen, en Yaxcabá, un pasado común. Esta situación no es peculiar del municipio de Yaxcabá. Eduardo Menéndez muestra que, en Yucatán, a diferencia de otros estados de México, se desarrolló desde tiempos antiguos la medicina alopática ${ }^{(16)}$.

¿Y por qué, entonces, no hacer una ceremonia para ese sitio Internet? Podría ser, además, la primera página para presentar el sitio, de manera que se entraría al sitio con este ritual. Así pues, decidimos, con Juan, que esta ceremonia tendría lugar a fines de ese mes (enero 2012). Juan ofrecería en sacrificio las aves necesarias y yo participaría también con algo de dinero. Unas semanas más tarde nos encontramos Juan y yo frente al altar, Juan cantando y yo filmando ${ }^{(17)}$.

Una ceremonia para un sitio Internet era un hecho sin precedentes hasta ese entonces, por consiguiente, estábamos creando juntos una nueva modalidad de ceremonia. Recordamos que una ofrenda se hace en dos tiempos: subir (ensik) y bajar (emik) y, entre los dos tiempos, los ancestros consumen las ofrendas, que luego son repartidas entre los asistentes a la ceremonia. Al momento de bajar las ofrendas, Juan, que ya había tomado un poco de alcohol, en la euforia del momento reparte inmediatamente el balche' a quienes están cerca de la mesa. Le hago la observación respecto a que esto no es muy ortodoxo porque primero se debe agradecer a los antepasados con un rezo y después repartir a los participantes la bebida ritual. Juan me cita entonces esa palabra improvisada de don Jas, un ilustre $h$-men de la zona que faIleció hace poco: “¡Lo que vas a hacer es así! ¡Lo vas a hacer a tu manera, con tu creencia, hazlo y es así!"

Toda transgresión se vuelve una nueva regla y mejor si es inspirada por un espíritu suhuy, puro, nuevo, original... Lo que caracteriza la palabra del $h$-men que llegó a la madurez de su arte, es su capacidad del suhuy t'an, es decir, de la "palabra nueva", "improvisada". Si consideramos el sentido de suhuy como "nuevo", que "nunca llegó a la luz del sol", entonces, el ritual debe permitir esa novedad, esa improvisación. Como un músico de jazz, el h-men conoce la música y por eso puede proponer nuevas tonadas, adaptando sus temas tradicionales.

\section{Las barajas y el diagnóstico}

El juego de barajas corresponde, para Juan, al reconocimiento del cuerpo del paciente por el médico alópata: “No entiendo sin bases pero busco para entender, reconozco el cuerpo..." dice Juan. Del mismo modo que los médicos auscultan su paciente y ven si tiene un dolor en tal o cual lugar, Juan no toca a su paciente pero ve, "lee" los dolores en las barajas. Sin embargo, no todas las enfermedades requieren sacar suerte. Juan saca suerte solo cuando puede estar involucrada la acción de un viento, un $i k^{\prime}$, es decir una fuerza vital ancestral. Por su parte, cuando el caso es simple, el tratamiento se hace con base en una conversación con el paciente.

Las barajas obedecen a reglas simples pero polisémicas y dejan libre el camino para las interpretaciones. Por ejemplo "el siete de espada significa una alteración de los nervios, un dolor muscular del cerebro, domina todo tu cuerpo...". El paciente escoge, entre dos, una baraja que lo va a representar y se leen entonces las cartas alrededor de esta. Si es hombre, o mujer anciana, el paciente escoge entre caballo de oro y de copa, y si es mujer entre sota de oro y de copa. Bastón y espada no pueden representar al paciente porque son cartas negativas, "malas". Si sale un siete de espada al lado de la baraja que representa al paciente, entonces Juan, interrogando al paciente, averigua si el valor de la carta corresponde a una situación física. El siete de oro significa dinero mal gastado... Juan no solo reconoce el cuerpo, sino también la mente: trata las afecciones psíquicas, problemas de dinero y del corazón... 
Cuando Juan ve un paciente por primera vez, en los primeros segundos, en el primer minuto, le llega un gran número de informaciones, pero en desorden y que, poco a poco, van a estructurarse con la lectura de las barajas. A veces, la pregunta del paciente es clara y la contestación evidente: una diarrea, un mal de ojo, un dolor muscular... Juan entonces se empeña en buscar la causa: natural o hechizo $y$, si es natural, si proviene de un $i k^{\prime}$, traducido en el español yucateco por "viento", o de otra causa... El trabajo de Jeanne Favret Saada ${ }^{(18)}$ permite comparar la técnica de Juan con la técnica de un curandero francés: aparecen a la vez diferencias pero también similitudes, por ejemplo, la capacidad de relacionar un número reducido de categorías con cierto universo y de establecer entre esas categorías y ese universo relaciones que tienen sentido para el paciente ${ }^{(18)}$.

Las nociones de viento/ik', hechizo/ pulyah, mal de ojo -no conozco equivalente en maya- son categorías como la infección, la gastritis, la conjuntivitis... Encontramos tratamientos comunes como un baño con una mezcla de sipche' (diferentes especies del género Bunchosia y Malpighia glabra), tankasche' (Zanthoxylum fagara) sinanche' (Zanthoxylum caribaeum, identificación que también puede corresponder al tankasche') y balche' (diferentes especies del género lonchocarpus) para tratar el viento ${ }^{(19,20)}$. Pero hay también complicaciones que necesitan tratamientos complementarios: una santiguación -forma dialectal del español hablado en la zona- o santiguada, un k'ex o un loh lu'um que implica también la curación del terreno del paciente si el ataque es más grave...

El k'ex "cambio" es una de las principales ceremonias de curación de los mayas yucatecos, se trata más bien del k'ex kuxtal en el cual una vida -generalmente la de un gaIlináceo (pollo, gallina o gallo)- es entregada a "cambio" de la vida del paciente. Ese ritual tiene elementos comunes con el "passer poule", ritual vudú originario de África del poniente y que se practica, desde la colonia, en la isla de Haití.

Loh es una categoría de ritual: conocemos el loh lu'um "liberación de la tierra", el loh kah "liberación del pueblo", el loh coral "liberación del corral". El loh lu'um, "liberación, purificación de la tierra", es una ceremonia que permite "curar" un lugar que no puede ser ocupado por humanos porque es habitado por los "vientepasados", ik'oob, antepasados míticos que tienen como esencia fundamental el viento. En español yucateco son designados como "vientos". En algunos casos, Juan no puede hacer el tratamiento solo, se necesita una operación espiritual y hay que acudir a un espiritista.

El término de $i k^{\prime}$, además de "viento" tiene también el significado de "antepasado mítico". Por esa razón, propuse traducirlo por el neologismo de "vencêtre" (en francés) y en español por "vientepasado"(3,21). Varios trabajos recientes trataron de entender la noción de viento y su acción en las enfermedades $^{(22,23)}$. El $i k^{\prime}$ es, según mis amigos e informantes, una energía cósmica que puede incorporarse en varios tipos de "seres" -empleo la noción de "ser" aunque no exista exactamente en maya yucateco- que pueden ser humanos, pero también animales, árboles, piedras... Cuando los "seres" son destruidos o "matados" -en yucateco se dice $p a^{\prime}$ $i k^{\prime}$ destruir la energía cósmica o viento- esa energía es liberada en el cosmos y queda disponible para nuevas encarnaciones ${ }^{(3)}$.

Para sacar la suerte, es decir, hacer un diagnóstico con barajas, pasamos al salón, una habitación grande, clara y agradable. Con frecuencia, una familia entera viene a consultar, ya que la suerte de ambos (paciente y familia) se relaciona, y la enfermedad de la madre o del padre hace eco a la enfermedad del hijo o de la hija.

No todos los pacientes conocen el ritual, por lo tanto, cuando no lo conocen, Juan indica los procedimientos: primero escoger una baraja entre dos, después, dividir en tres grupos las barajas restantes, y es en este orden que Juan va a disponer las cartas sobre la mesa. Así es el paciente quien determina -ya que, en la lógica chamánica no hay azar y todo está determinado- su destino y el $h$-men solo se encarga de interpretar.

En efecto, inmediatamente, una fatalidad envuelve al paciente y lo implica en la lectura 
de las barajas con el h-men. La lectura empieza y el diagnóstico progresa con ensayos y errores en relación con los sorteos sucesivos. Son tres, ox, y permiten confirmar, a veces informar, y precisar el primer diagnóstico. $O x$ es un nombre clave en la mitología maya, se asocia con la mujer y es también uno de los nombres de la madre cósmica en su identidad de ramón (Brosimum alicastrum). A nivel transcultural, es el arquetipo de la salida de la dualidad.

También el tratamiento progresa de acuerdo con las barajas y permite corregir errores. La lectura analógica de las barajas que comporta varias respuestas para una sola información- se hace dialogando con el paciente. Juan procede, generalmente, por afirmaciones que pueden o no ser confirmadas: "¿Masimá tienes dolores de cabeza de vez en cuando?" aunque la forma ortodoxa que generalmente se emplea es "es verdad que", y Juan así lo hace cuando habla español, mientras la forma "masimá" es criolla. Más raramente hace preguntas como " $i d u e r m e s$ bien de noche?" y, en relación con las respuestas, modifica su lectura. También se puede leer la suerte de una persona que no está presente, generalmente, sin que lo sepa el interesado $y$, en este caso, es porque se quiere intervenir sobre el destino de esta persona, cambiar nuestra relación con ella.

$\mathrm{Al}$ igual que cuando consulta a un médico alopático, el paciente sabe que el diagnóstico se basa sobre datos "objetivos", reflejados en las cartas, pero que esos datos son complejos y siempre deben ser interpretados. A veces conoce algunos signos pero, generalmente, no puede seguir la lógica de la lectura. Escucha entonces como un oráculo la lectura y puede o no creer en ella. Desde este punto de vista, la analogía con el médico alopático funciona: el paciente no sabe sobre cuales índices el médico basa su diagnóstico pero, a veces, puede aportar al médico un dato que este ignora e incluso le puede hacer modificar su diagnóstico. El paciente escucha entonces una "historia" que es a la vez una explicación de su historia: leyendo las cartas, el $h$-men a la vez completa el cuadro clínico y la historia de la enfermedad, de la "desgracia", y al mismo tiempo propone un tratamiento basado en plantas medicinales, rezos y rituales. Además, el tratamiento puede también ser aplicado sobre el terreno o la casa del paciente si el $h$-men observa que la causa de la enfermedad reside en una enfermedad ambiental.

El paciente se lleva entonces una explicación y puede entonces hacer su propio análisis: la historia y el tratamiento funciona o no... Por esa razón, se considera necesario que el paciente crea en la eficacia del tratamiento. Si no cree, no funciona. La relación de confianza, es decir, si empleamos el lenguaje técnico del psicoanálisis, la relación transferencial y contratransferencial, es fundamental. La contratransferencia designa la transferencia del psicoanalista sobre su paciente, en respuesta a la transferencia normal. Si no hay confianza, si la transferencia no opera, entonces el tratamiento no funciona. Incluso se dice de las plantas medicinales: "si no crees en su poder, no curan". Al contrario, en el caso de la medicina alopática, el medicamento puede teóricamente ser eficaz, independientemente de la confianza $y$, entonces, puede funcionar al margen de la cualidad de la relación humana. La cualidad del medicamento es más importante que la cualidad de la relación, la curación se vuelve entonces una mercancía, la venta de un medicamento que influye directamente sobre el dolor $\mathrm{y}$, para el paciente, sobre la enfermedad. Pero claro, eliminar el dolor no significa eliminar la enfermedad.

En el lenguaje corriente, esa relación de confianza se expresa simplemente así: "si no hay creencia, no funciona". La creencia en la eficacia del tratamiento $y$, en términos más espirituales, la creencia en la eficacia de la planta, es esencial para que el tratamiento funcione aun si se sabe que ciertas plantas son, de todos modos, efectivas. Cada familia conoce un número variable de plantas medicinales y las usan con frecuencia, pero incluso esa eficiencia depende de la creencia. Dicha creencia puede ir muy lejos en el caso de ciertos tratamientos en los que se escoge una planta sin conocerla y aun sin mirarla: así para el tratamiento de una mordida de 
culebra, si no hay medicina al alcance, solo se arranca, sin mirarla, la primera planta que esté atrás de uno mismo y se la unta en la Ilaga. Dos personas distintas, una en Cancún, originaria de Sotuta, y otra en Tabi, me contaron ese "secreto".

Podemos plantear la hipótesis según la cual disminuir el estrés es crucial en este caso. En otro caso, un dueño del monte muestra al soñador la planta en su lugar en el monte y este último solamente tiene que ir a buscarla cuando se despierta. Así lo expresa Fulgencio Albornoz en "Sueños de Iluvia":

Dormía así, era mi pixan, mi "espíritu" así. Y me iba en el monte, buscando medicinas cuando algo Ilegó. ¡Eeeh! Esa cosa habló:

- ¿Dónde vas?

- Estoy buscando medicinas pero no veo ninguna.

- Hay allá. Allá voy. Cuando quiero medicinas, hay en el terreno allá.

- Está bien.

- ¿De dónde vienes?

- De Tabi.

- Está bien.

No llegamos más lejos y dijo:

- Aquí está la medicina, janda en el terreno! Fue allá...

Pero la creencia siempre es relativa porque la salud es un proceso complejo y aleatorio. La existencia misma de una pluralidad de "médicos" y de "h-menes" implica, cada vez que una perturbación del estado de salud interviene, una elección sometida a ensayos y errores. Tanto el $h$-men como el médico solo conocen una historia parcial de la enfermedad o las enfermedades del paciente. Uno de los aspectos de esa historia, que no podemos aislar de la enfermedad misma, es la economía de la enfermedad, el papel del dinero en la salud.

\section{Dinero y sacrificio}

El intercambio de dinero, que hoy es la parte esencial de lo que recibe el $h$-men por el tratamiento, es también el componente de un "sacrificio" que tradicionalmente forma parte del tratamiento.

El sacrificio animal que todavía existe en algunos rituales como el $k^{\prime}$ ex o el loh era también acompañado "antaño" -y ese "antaño" puede remontar bastante lejos, antes de la conquista española- de "moneda", es decir, un equivalente general de todas las mercancías que se volvió hoy maestro de nuestros destinos.

Terminaré ese trabajo con un análisis del dinero, más específicamente, del dinero del diablo, ya que todo dinero es hoy dinero del diablo. La antigua moneda de kakaw (cacao) -teobroma, bebida de los dioses- no era todavía dinero del diablo incluso si había un componente destructor en su sustancia misma. En el caso del kakaw, su valor de uso era una semilla comestible con la cual se confeccionaba una bebida para el sacrificio. Era una moneda ideal para operar la transición del sacrificio tradicional de ofrenda de comida/bebida a los dioses a la ofrenda de moneda: en este caso los dioses se bebían la esencia del cacao, y los hombres bebían el atole de cacao, cumpliendo así con la destrucción necesaria de la moneda sin que se diera, como en el caso moderno, una acumulación en manos humanas. Más aún, todavía se utilizaba marginalmente el kakaw como moneda a principios del siglo XX (datos orales de Tabi).

Hoy en día, siempre se ofrece saka' con kakaw en el poniente de Campeche, pero en el estado de Yucatán, se reparte saka' con azúcar o miel. El saka', "agua blanca", es una bebida de maíz que se prepara con maíz y agua, sin cal. Es la bebida principal ofrecida a los "vientepasados" o $i k^{\prime}$ oob en las ceremonias.

\section{Dinero de la curación y dinero del diablo}

El dinero es un componente esencial del tratamiento tanto en la medicina tradicional como en la medicina alopática. Tradicionalmente -y debemos entender el término "tradicional" de manera diferente a "antiguo", 
"remoto", "apartado de los cambios"- el dinero, como acabamos de verlo, pertenece al diablo y no es una simple metáfora. Si necesitas dinero, si realmente lo que necesitas es dinero y quieres obtenerlo antes que nada, entonces, solo tienes que llamar al diablo y este llegará en seguida, con su buena cara, su buen vestido, su caballo, su buena palabra... y sus cuernos asomando bajo su sombrero. Y entonces te pedirá: "¿cuánto quieres?" Y te lo dará.

Pero después de siete años deberás devolverlo, entregándole tu alma, dicen los curas, pero aquí, en esa tierra del Mayab, el pago es más concreto: iras a trabajar en su rancho. Pero ¿dónde queda el rancho del diablo? Hoy el rancho del diablo es "el mundo entero". No hay lugares que no se encuentren, hoy en día, en el rancho del diablo. Entonces, cuando un hombre necesita dinero ¿qué hace? Pues se va a trabajar al rancho del diablo. Hoy el diablo también extendió su rancho a las ciudades de Mérida (Yucatán) y Cancún (Quintana Roo) donde construye sin parar nuevas casas con materiales senciIlos e intercambiables: el famoso bloque de cemento que se puede comprar por $\$ 7,50$ pesos (precio de marzo 2016), semejante al bloque de Lego de mi niñez.

El dinero del diablo también es el dinero que el paciente ofrece al médico o al h-men. Y mientras más enfermo esté, más dinero tiene que soltar, y más tu familia se agota para encontrar ese dinero y echarlo en un pozo sin fondo que también pertenece al diablo. Así toda "curación", todo esfuerzo para reencontrar la salud, pasa por una circulación de ese dinero diabólico, que se volvió diabólico porque se desconectó de su valor de uso, que ya no es comida o bebida para compartir, sino más bien moneda de papel que hoy tiene todos los colores del arco iris.

Regresando a la práctica de Juan y analizando el lugar del dinero, Juan tiene dos tipos de tarifa: a) una tarifa fija de 50 pesos que corresponde al precio de las hierbas medicinales, a granel o en pomada, como también a una lectura de barajas y b) una tarifa variable que corresponde a un tratamiento más complejo que podemos caracterizar como "ritual".
Los principales son el $k^{\prime} \mathrm{ex}^{(24)}$, el loh lu'um, el hets lu'um, "sostener la tierra" - los dos últimos curan el terreno, ya que no solo una persona puede estar enferma. En mi película Jardins mayas/Milpas y huertos mayas 1986-2016 (25), muestro un ejemplo de loh lu'um, realizado por don Jas, un famoso $h$ men de Canacón, hoy fallecido.

A diferencia del loh lu'um, el hets lu'um se hace generalmente cuando se va a usar el terreno por primera vez. Otra forma de hets es el hets mek "sostener el abrazo", "bautismo" maya que se hace a los tres meses para una niña y a los cuatro meses para un niño. También tenemos los rituales para hacer regresar a un amante o un marido y esos pueden ser muy costosos ya que el amor pertenece al campo turbio de las pulsiones, dominio del diablo.

Pero no todos los $h$-menes tienen esa relación balanceada con el dinero. Algunos trabajan directamente con el "maestro" y son reconocibles a la vez por la eficacia de su tratamiento -a la condición de creerlo- y por su costo exorbitante, el cual puede superar los 10.000 pesos, es decir aproximadamente tres meses de salario.

Si consideramos, ahora, al médico alópata, hay también, para sintetizar, dos modos de relación con el dinero: a) la medicina "gratuita" en las clínicas de los pueblos o en el famoso hospital público de Mérida, el O'Horán, cuya calidad es muy variable y puede ser mediocre, además de que es muy difícil obtener una consulta rápida, y b) la medicina "paga" que es medicina privada y a la cual se acude en la mayoría de los casos serios. Pero esa medicina privada, con algunas excepciones, es cara y se encarga de jalar todo el dinero disponible y muchas veces el campesino se queda endeudado: tiene entonces que pedir prestado al diablo e ¡ir a trabajar en su rancho para devolverlo!

No solo el campesino se endeuda, sino también los integrantes de la capa media pueden encontrarse en esa situación en el caso de una enfermedad grave. Si eres pobre, si ya se agotó tu dinero y tus posibilidades de recibir préstamo, entonces te queda una última posibilidad: morir. 
La enfermedad es entonces en Yucatán -pero no solo en Yucatán- lo que viene a agotar periódicamente las reservas que se acumularon con paciencia. Las historias de los que perdieron toda su fortuna por curar a un padre, un hijo, una esposa... son innumerables. Y la ausencia de verdadera cobertura social hace prosperar al diablo en Yucatán. Cuando la seguridad social sustituye al sacrificio familiar, entramos en otra lógica que no pertenece a la historia maya.

Si quieres escapar al diablo, tienes sin embargo una solución: volverte tú mismo un diablo, es decir, un político, un financiero o, mejor todavía, un narcotraficante que participa de los dos. Tal vez, me salí un poco del estudio de la medicina tradicional con este análisis del dinero del diablo, pero un análisis de la medicina que olvide la cuestión monetaria se apartaría de un punto clave de lo que observamos hoy en esta búsqueda, siempre insatisfecha, de la salud.

\section{¿Y las $\mathrm{X}$-menes?}

Me parece difícil escribir un artículo sobre el arte de Juan sin hablar de las mujeres que le han transmitido su arte y a las cuales, a su vez, él les sigue transmitiendo el suyo. La presencia de mujeres curanderas en la formación de Juan y en su equipo de trabajo contrasta con su ausencia en la mayoría de las descripciones de los antropólogos y de otros estudios de ciencias sociales sobre Yucatán. Hace poco, tuve que insistir para que no me suprimieran un apartado sobre la importancia de las $x$-menes ${ }^{(26)}$.

Las mujeres no son tan visibles como los hombres porque, generalmente, no hacen las ceremonias agrícolas; sin embargo, algunas descripciones mencionan la presencia de mujeres en ese tipo de ritual ${ }^{(27,28)}$. Pero esa presencia no es nueva. El psicólogo Jacob Grinberg-Zylberbaum, en un extenso trabajo sobre los chamanes de México, ya había entrevistado a varias $x$-menes que utilizaban las mismas herramientas que los hombres en sus ceremonias. Doña María, por ejemplo, explica la utilización de los sastunes (piedras adivinadoras) y x-tunes (agujón de raya) en su práctica ${ }^{(29,30)}$. También me entrevisté con varias $x$-menes que hacían ceremonias agrícolas y, en la zona centro, la hija de don Jas de Canacon había retomado parte de su trabajo. En el pueblo de Calkiní, de 10.000 habitantes en la parte norte de Campeche, entrevisté a doña Candy o doña Candita como se le apoda cariñosamente. Doña Candy es, como don Juan, una gran improvisadora. Tiene sesiones casi diariamente con sus "jefes", (aluxes, sastunes...). Tiene también varios alumnos que son sus "ahijados". Algunos de ellos viven en Cancún y otro en EE.UU. "Es muy bonito saber el poder del aire", dice Doña Candy. Ella traduce $i k^{\prime}$ por "aire" y no por "viento". El aire es una fuerza, un ser espiritual con quien puedes intercambiar: "El aire tú le das y él te da. El aire te da más de lo que tú le regalaste" (conversación del 26 de noviembre de 2012).

Doña Candy me explicó cómo tuvo la oportunidad de dirigir el trabajo de otros ocho $h$-menes en una ceremonia de gran importancia en el sitio prehispánico de X-pujil. Un anciano justificó esa selección porque "la mujer Balam (Balam kolel) es más fuerte que el hombre". Pude ver un video de ese ritual mientras doña Candy me lo comentaba ${ }^{(31)}$.

Patricia Balam y sus colegas $^{(28)}$ describen un matan $k^{\prime} O l$, ofrecimiento de $k^{\prime} O l$, una comida ceremonial típica de los yucatecos, parecida a la salsa "bechamel" francesa, con caldo de pollo o pavo, masa de maíz y recado a base de achiote. En esta ceremonia, oficia una rezadora. Esa rezadora que fue Ilamada "chamana" por unos estudiantes del centro de la república mexicana y después empezó a llamarse así. Observamos aquí la recuperación de la cultura maya por la cultura "new age", a la cual los curanderos mayas tienen que adaptarse. Doña Candy, por su parte, rechaza el término de chamán porque los chamanes vienen de México: "No dices que eres chamán, los chamanes son brujos, tú eres simplemente curandero". En el caso del matan k'ol de Muna, la "chamana" es más bien una rezadora. Las rezadoras son especialistas muy antiguas y conocidas en las ceremonias yucatecas $y$, a veces, pueden oficiar 
en partes preliminares de un ritual agrícola, como lo observé, por ejemplo, en Tabi, en las rogativas que preceden al cha'chak. En la descripción de sus rezos, podemos notar una predominancia del idioma español con rezos católicos, lo cual es característico de las rezadoras, pero no de las x-menes. Reza también un poco en maya pero, desgraciadamente, no tenemos la transcripción de su payalchi' o rezo. Nuevas investigaciones deberían permitir entender mejor el papel de las $x$-menes en la religión popular de los Yucatecos.

En combinación con la ceguera de los antropólogos, podemos detallar varios factores de la subestimación de la presencia de las $x$-menes:

a. El primero, y el más antiguo, es la eliminación de las mujeres chamanes por la inquisición española, en continuidad con la matanza de las "brujas" europeas a partir del siglo XIV. Bernardo Caamal Itza, agrónomo y periodista yucateco, mencionó en una conversación privada (abril 2016) que su abuela le hacía comentarios sobre esas matanzas de mujeres chamanes en Yucatán. Las fuentes escritas hablan más de hombres, incluso en la represión, que de mujeres ${ }^{(9)}$.

b.Las x-menes, salvo algunas excepciones, en general están ausentes en las ceremonias agrícolas, como el cha'chak (ceremonia de la lluvia), el hanlikol (comida de la milpa) o el matan $k^{\prime} O l$ (ofrecimiento de $k^{\prime} O l$ o salsa roja).

c. La división bastante estricta entre hombres y mujeres hace que los hombres, generalmente, no tengan acceso a los rituales femeninos y que las $x$-menes puedan desconfiar de un investigador masculino. Así, hace unos 20 años, una x-men de Yaxcabá, el pueblo de Juan, no quiso que yo me entrevistara con ella.

\section{UNA NUEVA PERSPECTIVA SOBRE LA TRADICIÓN}

La tradición en Yucatán es un conjunto dinámico abierto a los cambios y, a veces, los provoca. Como escribe Eric Hobsbawn "las tradiciones que parecen o reclaman ser antiguas son a menudo bastante recientes en su origen $y$, a veces, inventadas" ${ }^{\prime \prime 22}$. Reconocer la función central de la improvisación, como uno de los conceptos más importantes del pensamiento maya, nos abre nuevas perspectivas no solo para el estudio del pensamiento maya, sino también para el estudio del pensamiento tradicional en general.

El ejemplo yucateco nos parece indicar que la creación de la tradición no sería solamente una forma reciente que caracteriza las sociedades modernas, sino también una modalidad esencial de la relación entre cambio y continuidad en los procesos sociales. Nos podemos preguntar si, más que las prácticas tradicionales, no son los prejuicios de los sociólogos y de los antropólogos los que contribuyeron a dar una visión inmóvil de la tradición.

En toda cultura, existen conservadores e innovadores y Juan, como el finado don Jas, es ciertamente innovador. Si combinamos ese concepto con el concepto de xa'ak' "mezcla/ mestizaje"(26) y de way "metamorfosis", "ser en porvenir", podemos tratar de profundizar conceptos claves de nuestra filosofía, como son el concepto de "ser" o de "origen". Si buscamos una comprensión transcultural, debemos evitar utilizar los conceptos occidentales como claves, y trabajar esos conceptos a la luz de conceptos de otras culturas en otros idiomas.

Para terminar, partiendo del pensamiento maya, quiero proponer otro término diferente al de "tradición" para designar esas prácticas, a la vez antiguas y nuevas nos acordaremos que "nuevo" es uno de los sentidos de suhuy- que son parte del arte de don Juan. Centrándome en los conceptos de $x a^{\prime} a k^{\prime}$ y de suhuy, propongo designar la tradición como el lugar de un "mestizaje original" que se opone y completa a la vez la noción de pureza que también es uno de los sentidos de suhuy. Cuando un nuevo elemento se introduce en su práctica, don Juan se apoya sobre este mestizaje original para, de forma improvisada, proponer una nueva práctica que puede "inmediatamente" volverse tradición. 


\section{AGRADECIMIENTOS}

Este trabajo es el producto de varias investigaciones desarrolladas desde 1989 con el apoyo del Centre National de la Recherche Scientifique (CNRS - Paris). Agradezco a mi amigo Juan Cob Balam, quien es coautor de ese artículo, aunque no lo firmó. También agradezco a José Hernández la relectura y revisión ortográfica de mi texto.

\section{REFERENCIAS}

1. Ritual of the bacabs: manuscript, [between 1775 and 1800]. Localizado en: Robert Garrett Collection (C0744), Princeton University Library.

2. Arzápalo Marín R. El Ritual de los Bacabes: edición facsimilar con transcripción rítmica, traducción, notas, índice, glosario y cómputos estadístico. México: UNAM; 1987.

3. Boccara M. Herramientas de investigacion: Vocabulario, bibliografia, glosario. In: Los Laberintos sonoros: Enciclopedia de la mitología maya yucateca. Paris: CNRS, Université de Picardie Jules Verne, Université Diderot Paris 7; 2005.

4. Boccara M. Saints, chamanes et pasteurs: La religion populaire des Mayas II. Paris: L'Harmattan; 2011.

5. Boccara M. Une conversation avec don Juan, (psychiatrie maya traditionnelle). [Film, vidéo] URA 1478 CNRS. Paris: Mnémosyne, IRESCO Vidéo, La parole a le geste; 1993.

6. Boccara M, Capelle P. Sociomytho-logies de I'arbre: voyages entre ciel et terre. Paris: Le Temps Présent; 2013.

7. Tomasi di Lampedusa G. Le Guépard (1958). Paris: Le Seuil; 2007.

8. Barrera Vásquez A. (dir.). Diccionario maya Cordemex, maya-español, español-maya. Mérida, Yucatán: Cordemex; 1980.

9. Quijada D. Don Diego Quijada, alcalde mayor de Yucatán, 1561-1565: documentos sacados de los archivos de España y publicados por France $\mathrm{V}$ Scholes y Eleanor B Adams. México: Antigua Librería Robredo, de José Porrua e hijos; 1938.

10. Restall M. The black middle: Africans, Mayas, and Spaniards in Colonial Yucatan. Standford: Standford University Press; 2009.

11. Mayoli GF. El libro del judío. Mérida, Yucatán: José Martín y Espinosa de los Monteros; 1834.
12. Osado R, Barrera A, Barrera Vásquez A. El libro del judío su ubicación en la tradición botánica y en la medicina tradicional yucatanense. México: Instituto Nacional de Investigaciones sobre Recursos Bióticos; 1983.

13. Bergé C. L'au-delà et les Lyonnais, Mages, médiums et francs-maçons du XVIIlè au XXè siècle. Lyon: LUGD; 1995.

14. Hernández JJ. Costumbres de las Indias de Yucatán. Registro Yucateco. 1846;|III:290-298.

15. Boccara M. Chak y sus caballos: mitologia de la lluvia y de la fertilidad. In: Los Laberintos sonoros, Enciclopedia de la mitología maya yucateca. Paris: CNRS, Université de Picardie Jules Verne, Université Diderot Paris 7; 2005.

16. Menéndez EL. Poder, estratificación y salud: Análisis de las condiciones sociales y económicas de la enfermedad en Yucatán. México: Centro de Investigaciones y Estudios Superiores en Antropología Social; 1981.

17. Boccara M, Kob J. Une cérémonie improvisée. [Film, vidéo]. Paris: La parole a le geste, CNRS; 2012 [citado 10 may 2016]. Disponible en: https:// goo.gl/dGhnTi.

18. Favret-Saada J, Contreras J. Comment produire de l'énergie avec deux jeux de cartes. Bulletin d'ethnomédecine. 1983;24:3-36.

19. Arellano Rodríguez JA, Flores Guido JS, Tun Garrido J, Cruz Bojórquez MM. (ed.). Etnoflora yucatanense: nomenclatura, forma de vida, uso, manejo y distribución de las especies vegetales de la Península de Yucatán. Mérida: Universidad Autónoma de Yucatán; 2003.

20. Barrera Marín A, Barrera Vásquez A, López Franco RM. Nomenclatura etnobotánica maya: una interpretación taxonómica. México: INAH; 1976.

21. Boccara M. Vivir es hacer, volverse "vientepasado" o la maestría del espacio transicional. In: Breton A, Monod Becquelin A, Ruz MH. (ed.). Los espacios mayas: usos, representaciones, creencias. México: Universidad Nacional Autónoma de México, Centro Francés de Estudios Mexicanos y Centroamericanos; 2003.

22. Quintal E, Quiñones T, Rejón L, Gómez J. El cuerpo, la sangre y el viento: Persona y curación entre los mayas peninsulares. In: Bartolomé MA, Barabas A. (coords.). Los sueños y los días: Chamanismo y nahualismo en el México actual. México: INAH; 2013. p. 57-94.

23. Quintal E, Briceño F, Cabrera, A. Los que hablan con los vientos: Los jmeeno'ob. In: Bar- 
tolomé MA, Barabas A. (coords.). Los sueños y los días: Chamanismo y nahualismo en el México actual. México: INAH; 2013. p. 143-198.

24. Boccara M. La religion populaire des Mayas: Entre métamorphose et sacrifice. Paris: L'harmattan; 1989.

25. Boccara M. Jardins mayas/Milpas y huertos mayas, 1986-2016. [Film, vidéo]. Paris: La parole a le geste, CNRS; 2016.

26. Boccara M. Au pays des Mayas métis. Anthropologie et Sociétés. 2014;38(2):109-130.

27. Boccara M. Les chevaux de Pluie. [Film, vidéo]. Paris: Mnémosyne, CNRS Audiovisuel, ORSTOM Audiovisuel, La parole a le geste; 1987.

28. Balam P, Ruiz I, Solís I. Máatankól: la flexibilidad en el ritual. Estudios de Cultural Maya. 2009;XXXIV:145-143.
29. Grinberg-Zylberbaum J. Los chamanes de México (tomo 2). México: Facultad de Psicología, Universidad Nacional Autónoma de México; 1989.

30. Grinberg-Zylberbaum J. Los chamanes de México (tomo 4). México: Facultad de Psicología, Universidad Nacional Autónoma de México; 1991.

31. Il est très beau de connaître le pouvoir de I'air/Es muy bonito saber el poder del aire, doña Candita, x-men de Calkiní. [Film, vidéo]. Paris: La parole a le geste, CAS du LISST; 2017.

32. Hobsbawn E. La invención de la tradición. In: Hobsbawn E, Ranger T. (ed.). La invención de la tradición. Barcelona: Crítica; 2002. p. 7-21.

\section{FORMA DE CITAR}

Boccara M. Tradición, improvisación y modernidad en el chamanismo maya yucateco: El arte suhuy de Juan Cob, h-men de Yaxcabá. Salud Colectiva. 2017;13(3):429-442. doi: 10.18294/sc.2017.1077.

Recibido: 1 de agosto de 2016 | Versión final: 25 de enero de 2017 | Aprobado: 26 de abril de 2017

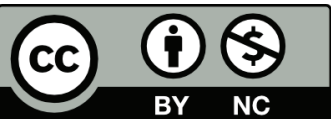

ste obra está bajo una licencia de Creative Commons Reconocimiento-NoComercial 4.0

Internacional. Reconocimiento - Permite copiar, distribuir y comunicar públicamente la obra.

A cambio, se debe reconocer y citar al autor original. No Comercial - Esta obra no puede ser

utilizada con finalidades comerciales, a menos que se obtenga el permiso.

http://dx.doi.org/10.18294/sc.2017.1077 